BONDING IN INORGANIC COMPOUNDS:

A STUDY BY X-RAY PHOTOELECTRON SPECTROSCOPY

October 1978

Steven Charles Avanzino

Lawrence Berkeley Laboratory University of California Berkeley, California

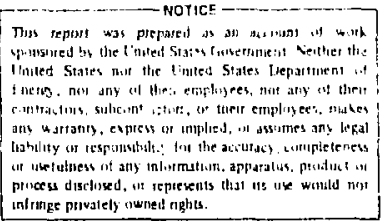


BONDING IN INORGANIC COMPOUNDS:

\section{A STUDY BY X-RAY PHOTOELECTRON SPECTROSCOPY}

\section{Contents}

ABSTRACT V

INTRODUCTION

1. An X-Ray Photoelectron Spectroscopy Study of 5 Volatile Tin Compounds

11. Core Binding Energies of Some Metal B-Diketonates 13 and $\beta$-Diketones in the Yapor Phase

III. A Study of Bridging and Terminal Carbonyl Groups 18 in Transition Metal Complexes by $X$-Ray Photoelectron Spectroscopy

IV. Use of Oxygen is Binding Energies and MultiplicityWeighted C-O Stretching Frequencies to Measure Back-Bonding in Transition Metal-Carbonyl Complexes

V. Distinguishing Axial and Equatorial Carbonyl Groups in Iron Pentacarbonyl by ESCA

VI. A Study of Pentacarbonylmanganese Complexes by Gas-Phase X-Ray Photoelectron Spectroscopy

VII. A Simple Method for Obtaining X-Ray Photoelectron Spectra of Species in Liquid Solutions

VIII. Evidence for Hyperconjugation from an X-Ray

Photoelectron Spectroscopic Study of Isoelectronic Compounds

IX. The Core Electron Binding Energies of Cyclotriphosphazenes and Cyclotetraphosphazenes

$x$. The Core Electron Binding Energies of Gaseous Chlorine Monofluoride 
BONDING IN INORGANIC COMPOUNDS:

A STUDY BY X-RAY PHOTOELECTRON SPECTROSCOPY
\end{abstract}

Steven Charles Avanzino

ABSTRACT

Core electron binding energies were measured for a variety of inorganic and organometallic compounds using gas-phase $X$-ray photoelectron spectroscopy (XPS). The atomic charge distributions in these molecules are deduced from the binding energies, often leading to a better understanding of the bonding in these compounds.

The XPS spectra of fifteen volatile tin compounds were recorded. The tin binding energies are well correlated by the "transition state" point-charge potential model equation using atomic charges calculated by the CHELEQ electronegativity equalization method. The core binding energies of some tris $\beta$-diketonates of $A I$ (III), V(III), $C r(I I I)$, and Fe(III) were measured. The large shifts observed for the $A 12 p$ energies are believed to be caused mainly by changes in the molecular electrostatic potential at the $A 1$ atom. The data suggest that the metal d orbitals are not significantly involved in the bonding.

The oxygen is XPS spectra of gaseous $\mathrm{CH}_{3} \mathrm{Mn}(\mathrm{CO})_{5},\left[\pi-\mathrm{C}_{5} \mathrm{H}_{5} \mathrm{Fe}(\mathrm{CO})_{2}\right]_{2}$, and $\mathrm{CO}_{4}(\mathrm{CO})_{12}$ can be readily resolved into separate peaks due to bridging and terminal carbonyl groups. The 0 is binding energy of a bridging carbonyl group is lower than that of a terminal carbonyl group, which is consistent with recent structural assignments of 0 is spectra of 
carbon monoxide adsorbed on metal surfaces. The 0 is spectrum of $\mathrm{Fe}(\mathrm{CO})_{5}$ obtained with a high-resolution spectrometer is deconvoluted into cwo peaks characteristic of the axial and equatorial carbonyl groups in the molecule. The $\mathrm{C}$ 1s spectrum of $\mathrm{Fe}(\mathrm{CO})_{5}$ consists of a single symmetric peak. The carbonyl ligand core binding energies of transition-metal carbonyl complexes are sensitive to differences in the metal-to-CO ligand bonding. Both $\mathrm{C}$ is and $\mathrm{O}$ is carbonyl binding energies correlate well with average $\mathrm{C}-\mathrm{O}$ stretching force constants or average C-0 stretching frequencies. The metal and carbonyl binding energies in a series of pentacarbonylmanganese complexes $\mathrm{LMn}(\mathrm{CO})_{5}$ are a good measure of the relative electronegativities of the ligands $\mathrm{L}$. However, these binding energies could not be used to determine the relative $\sigma$ - and $\pi$ - acceptor abilities of the ligands L. Strong shake-up satellite lines are observed in the core-level spectra of the carbonyl ligand atoms of $\mathrm{LMn}(\mathrm{CO})_{5}$, and they are attributed to a process involving metal-to-ligand charge-transfer transitions.

High-quality $X$-ray photoelectron spectra have been obtained for compounds dissolved in glycerin solutions, and aqueous solutions were converted into glycerin solutions which gave good XPS spectra of the solutes. The technique appears promising as a future analytical application of X-ray photoelectron spectroscopy.

The shifts in the binding energies of oxygen, chlorine, and carbon atoms in some isoelectronic isostructural compounds can be explained in terms of simple trends in atomic charges. However, the fluorine is binding energies for some fluoro compounds of silicon, phesphorus, sulfur, and chlorine show unusual shifts which suggest that 
hyperconjugation is important in the bonding of these compounds. The core binding energies of the cyclic phosphazenes $\left(\mathrm{NPF}_{2}\right)_{3},\left(\mathrm{NPF}_{2}\right)_{4}$, $\left(\mathrm{NPCl}_{2}\right)_{3},\left(\mathrm{NPCl}_{2}\right)_{4}$, and $\left[\mathrm{NP}\left(\mathrm{CH}_{3}\right)_{2}\right]_{4}$ were measured. On going from $\left(\mathrm{NPF}_{2}\right)_{4}$ to $\left(\mathrm{NPF}_{2}\right)_{3}$ or from $\left(\mathrm{NPCl}_{2}\right)_{4}$ to $\left(\mathrm{NPCl}_{2}\right)_{3}$, the binding energies increase by only $0.22 \mathrm{ek}$ or less, suggesting that the degree of $\pi$ bonding is similar in the trimers and tetramers. The core binding energies of chiorine monofluoride were remeasured and were found to differ considerably from previously published values. Atomic charges in this molecule are estimated from binding energies using the pointcharge potential model. 


\section{INTRODUCTION}

X-ray photoelectron spectroscopy (XPS or ESCA) has proven to be a useful tool for the chemist interested in the electronic structure of matter. This thesis represents an attempt to apply gas-phase $X$-ray photoelectron spectroscopy to inorganic and organometallic compounds. From XPS measurements the atomic charge distribution in these molecules can be deduced leading to a better understanding of the bonding.

The usual quantity derived from an XPS experimerit is the core electron binding energy $E_{B}$. In a typical gas-phase XPS experiment, sample vapors are introduced into the irradiation chamber of the spectrometer by means of a continuous-flow system. Here the sample is irradiated by the characteristic $\mathrm{MgK}_{\alpha 1,2} X$-ray 1 ine resulting in the photo-einction of electrons spanning a range of kinetic encrgy $E_{k}$. The photoelectrons enter a dispersion analyzer capable of resolving the different electron energies into a kinetic energy spectrum. This is accomplished by means of electrostatic or magnetic focusing of the beam so that electrons of a given $E_{k}$ are spatially separated from electrons of different energies. The electrons are detected and recorded as a function of their kinetic evergy. The peaks in a spectrum correspond to photoelectrons from a given core level whose binding energy

$$
E_{B}=h v-E_{k}
$$

is calculated from the known $X$-ray photon energy $h v$ and the measured kinetic energy of the photoelectrons.

The binding energy for a given core level in an isolated molecule is the total energy of the molecular core-ion (formed by the 
photoionization process) minus the total energy of the ground state molecule:

$$
E_{B}=E_{\text {ion }}-E_{0}
$$

In general, significant differences between $E_{i o n}$ and $E_{0}$ arise from the electronic contribution to the total energies $\left(E_{\text {elec }}+E_{v i b}+E_{\text {rot }}+\right.$ $E_{\text {trans }}$ ) of the two species. Thi feature of the core binding energy of most interest to the chemist is the chemical shift observed from one compound to another. Binding energy shifts can often be interpreted in terms of differences in the ground-state valence electron distribution between molecules. By applying Koopman's Theorem, Eqn. (2) can be written as

$$
E_{B}=\left(E_{i \text { in }}^{K T}-E_{0}\right)-E_{R}
$$

where $E_{i o n}^{K T}$ is the total energy of the core-ion assuming that all orbitals remain "frozen" and do not relax upon the creation of a core hole, and $E_{R}$ is a correction term to account for this relaxat,ion which does indeed occur. When Eq. (3) is used to describe binding energy shifts

$$
\Delta E_{B}=\Delta\left(E_{\text {ion }}^{K T}-E_{0}\right)-\Delta E_{R}
$$

the $\Delta\left(E_{i \text { on }}{ }^{K T}-E_{0}\right)$ term relates to differences in ground-state electronic structure between compounds. The point-charge potential madel is often used to approximate $\Delta\left(E_{i o n}{ }_{i o n}-E_{0}\right)$ in terms of physical quantities more significant to the chemist. According to the model, changes in the quantity $\left(E_{i o n}^{K T}-E_{0}\right)$ are due to changes in the electrostatic poteintial felt by the core electron due to differences in the distribution of valence electrons. The model assumes a spherical electron distribution 
about each nucleus so that the potential arises from the net charge on each atom located at the respective nucleus. The expression for binding energy shift now includes the useful quantity atomic charge:

$$
\Delta E_{B}=k \Delta Q_{j}+\Delta V_{i}-\Delta E_{R}
$$

where $Q_{j}$ is the ground-state atomic charge on the core-ionizing atom, $v_{i}\left(=\sum_{j \neq i} Q_{j} / R_{i j}\right)$ is the potential due to the other charged atoms in the molecule, and $k$ is the binding energy change attributed to a unit change in atomic charge.

Many workers in this field have applied the relationship of Eqn. (5) to chemical systems in different degrees of sophistication. Quite often one equates binding energy shifts solely to changes in atomic charge on the ionizing atom, neglecting the potential term and the relaxation energy correction. Other more elaborate studies include one or both of these second-order terms thich often give more satisfactory results for a structurally-unrelated series of compounds. In this work binding energy shifts have been interpreted in different circumstances using one of these three levels of theoretical sophistication.

The greater part of this thes is is comprised of eight articles which have been published in the chemical literature over the past three years. Each of the articles has been co-authored by me and contains research that I have conducted in my doctoral studies. In order that the reader may appraise my contribution to the work contained in the publication reprints, the following table is included in this introduction. 


\begin{tabular}{lcccc}
\hline Percentage & $\begin{array}{l}\text { Involvement in: } \\
\text { Synthesis of } \\
\text { Compounds }\end{array}$ & XPS Experiments & Calculations & $\begin{array}{c}\text { Drafting of } \\
\text { Article }\end{array}$ \\
\hline I & $100 \%$ & $100 \%$ & $75 \%$ & $75 \%$ \\
II & $0 \%$ & $25 \%$ & $100 \%$ & $20 \%$ \\
III & $100 \%$ & $100 \%$ & $\star$ & $25 \%$ \\
IV & $10 \%$ & $10 \%$ & $90 \%$ & $20 \%$ \\
V & $0 \%$ & $0 \%$ & $100 \%$ & $75 \%$ \\
VI & $100 \%$ & $100 \%$ & $100 \%$ & $90 \%$ \\
VII & $\star$ & $100 \%$ & $\star$ & $90 \%$ \\
VIII & $15 \%$ & $20 \%$ & $\star$ & $10 \%$ \\
IX & $\star$ & $60 \%$ & $100 \%$ & $20 \%$ \\
$X$ & $\star$ & $75 \%$ & $100 \%$ & $90 \%$ \\
\hline
\end{tabular}

* Not applicable. 


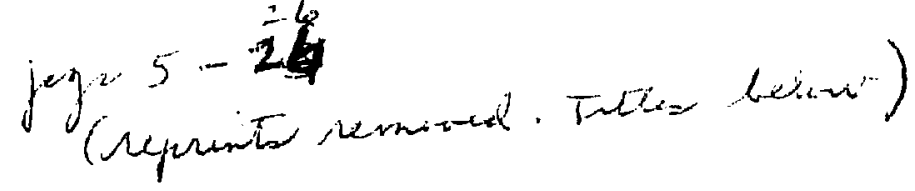

Journal of Electron Spectroscopy and Related Phenomena, 8 (1976) 15-22

() Elsevier Scientific Publishing Company, Amsterdam - Printed in The Netherlands

\title{
AN X-RAY PHOTOELECTRON SPECTROSCOPY STUDY OF VOLATILE TIN COMPOUNDS*
}

STEVEN C. AVANZINO and WILLIAM L. JOLLY"*

The Department of Chemistry, University of California, and the Inorganic Moterials Research Division, Lawrence Berkeley Laboratory, Berkeley, California 94720 (U.S.A.)

(Received 22 May 1975)

J. $\mathrm{C}$ ord. Ohem.

1970, vol. 5, pp. 157-161
(C) Gordon and Breach Science Publishers Lid., 1976

Printed in Greal Britain

\section{CORE BINDING ENERGIES OF SOME METAL $\beta$-DIKETONATES AND $\beta$-DIKETONES IN THE VAPOR PHASE}

\author{
THEODORE F. SCHAAF, STEVEN C. AVANZINO, WILLIAM L. JOLLY
}

Department of Chemistry, University of California, and Inorganic Materials Research Division,

Lawrence Berkeley Laboratory, Berkeley, Califomia 94720, U.S.A.

and

ROBERT E. SIEVERS

Department of Chemistry, University of Colorado, Boulder, Colorado 80302. U.S.A.

\section{A Study of Bridging and Terminal Carbonyl Groups in Transition Metal Complexes by X-Ray \\ Photoelectron Spectroscopy}

\section{Steven C. Avanzino and William L. Jolly*}

Consribution from the Materials and Molecular Research Division.

Lawrence Berkeley Laboratory, and Department of Chemistry.

University of California. Berkeley. California 94720. Received March 1, 1976

[Reprinted from Inorganic Chemistry, 16, 964 (1977).]

Copyright 1977 by the American Chemical Society and reprinted by permiseion of the copyright owner.

\section{Uee of Oxycen is Binding Dectites and \\ Muldiplielty-Weighted C-O Stretchlog \\ Frenpencles to Menvere Back-Bonding in Trualtion \\ Metal-Carbogl Conglexes}

William L. Jolly, Steven C. Avanzino, and Richerd R. Rietz

[Reprinled from Inorganic Chemistry, 17, 489 (1978).]

Copyright 1978 by the American Chemical Society and reprinted by permission of the copyright owner

\section{Distinguishing Axial and Equaterial Carbonyl Groups in \\ Iron Pentacarbonyl by ESCA}

S. C Avanzino," W. L. Jolly, *" P.-A. Malmquist,

and $\mathrm{k}$. Siegbahn'b 


\section{A Study of Pentacarbonylmanganese Complexes \\ by Gas-Phase X-Ray Photoelectron Spectroscopy}

Manganese(I) forms a large number of stable six-coordinate carbonyl complexes of the type $\operatorname{LMn}\left(\mathrm{CO}_{5}\right.$ which may be considered as complexes of $\operatorname{Mn}(\mathrm{CO})_{5}^{+}$with various anionic ligands, $L$. The metal-ligand bonding interactions in these compounds are thought to be a mixture of both $\sigma$ - and $\pi$-bonds. The $\sigma$-bonding orbitals are formed by the overlap of filled o orbitals on the ligands $L$ or $C O$ with the empty orbitals of $\sigma$-symetry on the central metal atom. The $\pi$-bonding orbita\}s are formed when filled metal di orbitals overlap with empty orbitals of $\pi$-symmetry on the ligands $L$ or $c 0 .^{1}$ The effect of a ligand $L$ upon the electron density distribution in the rest of the molecule will depend upon the $\sigma$ - and $\pi$-bonding ability of the ligand.

We have measured the core electron binding energies of twelve compounds of the type $\mathrm{LMn}(\mathrm{CO})_{5}$ by gas-phase $x$-ray photoelectron spectroscopy in an attempt to study the bonding characteristics of the ligands L. Only two of these compounds $\left(\mathrm{L}=\mathrm{H}^{-}, \mathrm{CH}_{3}{ }^{-}\right.$) have been previously studied in the gas phase by XPS. ${ }^{2}$ There appear in the literature a number of theoretical ${ }^{3-6}$ and UV photoelectron spectroscopy ${ }^{7,8}$ studies involving hydrido-, halogeno-, methyl-, and perfluoromethylpentacarbonylmanganese.

Core Binding Energy Shifts

The binding energy data are shown in Table I and Table II. The compounds are listed in the order of their increasing manganese binding energies, which span a range of $\sim 1 \mathrm{eV}$. Note that the trends in the 
carbonyl carbon and oxygen binding energies both parallei the trend in the manganese binding energy. Figures 1 and 2 show plots of carbon and oxygen binding energies vs. manganese binding energy for the compounds studied. $E_{B}(C 15)$ and $E_{B}(015)$ show a high correlation with $E_{B}\left(M_{n} 2 p_{3 / 2}\right)$ within the indicated experimental uncertainty. It is interesting that the carbon and oxygen binding energies increase by almost the same amount as the manganese binding energy. This does not mean that the carbon and axygen charges change to the same extent as the manganese charge on going from one compound to the next. One can relate binding energy shifts to atomic charge changes by the potential mode ${ }^{9}$

$$
\Delta E_{B}=k \Delta Q+\Delta V
$$

in which the $k \Delta Q$ term usually predominates. Since the magnitude ${ }^{10}$ of $k$ for carbon $\left(k_{C}=24.0 \mathrm{eV} / e\right)$ and oxygen $\left(k_{0}=27.2 \mathrm{eV} / \mathrm{e}\right)$ is greater than for manganese $\left(k_{M n}=11.7 \mathrm{ev} / e\right)$, the binding energy data are consistent with the expected changes in electron distribution based on inductive effects, i.e., greater changes in the manganese charges than in the carbon or oxygen charges.

The manganese binding energies of our $\mathrm{LMn}(\mathrm{CO})_{5}$ series are in general accord with other indicators of the atomic charge on the manganese atom. Table III shows a group of compounds for which data from ionization potential measurements (UPS), ${ }^{7,8}$ molecular orbital calculations, ${ }^{3}$ and electronegativity estimates ${ }^{11,12}$ are available. In general, an increase in the manganese core binding energy and the manganese $3 d$ ionization potential corresponds to the increased electronegativity of the ligand $L$ and the decreased electron occupation for manganese orbitals. 
Recent XPS studies ${ }^{13,14}$ by the authors were able to distinguish bridging and terminal carbonyl groups in transition metal complexes; however, terminally-bound axial and equatorial carbonyl groups were barely distinguishable even using a spectrometer with extremely high resolution. Separate peaks for the axial and equatorial co ligands in $\mathrm{LMn}(\mathrm{CO})_{5}$ compounds are beyond the resolution capabilities of our instrument. All one can hope to observe is a "weighted-average" spectrum for the one axial and the four equatorial carbonyl ligarids. This is an unfortunate situation, because axial and equatorial ligand binding energies should be affected differently by the $\sigma$ and $\pi$ bonding abilities of $L$, as are the axial and equatorial co stretching force constants. 15 One way to distinguish the differences in $\sigma-$ and $\pi$-ability of ligands-short of determining separate axial and equatorial CO binding energies-would involve a careful inspection of the trends in the manganese, carbon, and oxygen binding energies. For instance, if the $\mathrm{CO}$ binding energies were influenced more by a ligand's $\pi$ - rather than $\sigma$-ability than was the manganese binding energy, one might observe marked deviations of certain points from the linear correlations of carbonyl vs. manganese binding energies. The points for $\mathrm{CIMn}\left(\mathrm{CO}_{5}\right.$ and $\mathrm{BrMn}(\mathrm{CO})_{5}$, in which chlorine and bromine are good $\sigma$-acceptors but have no $\pi$-acceptor ability, would lie below a line through the compounds in which the $\pi$-acceptor ability of a ligand paralleled its o-acceptor ability. The binding energy plot in Figure 1 barely suggests this effect for chlorine and bromine, but we believe no conclusions should be drawn from these minor deviations. Unfortunately, we are not abi to differentiate the $\sigma$ vs. $\pi$ bonding abilities of $L$ by measuring core binding energies in 
these compounds.

Carbonyl force constants are sensitive to electron deneity backbonded into the $\pi^{*} \mathrm{CO}$ orbitals. Hall and Fenske ${ }^{6}$ have shown that their calculated electron occupancies of the carbony $15 \sigma$ and $2 \pi$ orbitals correlate with $\mathrm{CO}$ force constants. The carbonyl ligand binding energies should also be influenced by electron density transferred from the metal to the CO ligands. Consequently, one might expect CO ligand binding energies to correlate with $\mathrm{CO}$ force constants. Our $\mathrm{LMn}(\mathrm{CO})_{5}$ carbon and oxygen binding energies do indeed correlate with the weighted-average ${ }^{16}$ C0 force constants (correl. coeff. $=0.97$ (C), $0.96(0)$ ), and it is not surprising that the manganese binding energies likewise correlate with $k_{\text {avg }}^{\mathrm{CO}}$ (correl. coeff. $=0.98$ ) in view of the observed proportionality of the three core-level binding energies. The correlations for carbon, oxygen, and manganese are illustrated in Figures 3, 4, and 5, respertively.

Recently we have illustrated the relationship between $C O$ ligand 015 binding energies and the degeneracy-weighted average infrared C-0 stretching frequency for a more general series of metal carbonyl complexes. ${ }^{17}$ Weighted-average co force constants are directly proportional to degeneracy-weighted averáge C-0 stretching frequencies; ${ }^{14}$ consequently, 0 is binding energies should correlate with the former as well as with the latter. He now extend the series of metal carbonyl complexes in Reference 17 to include most of our $\operatorname{LMn}(\mathrm{CO})_{5}$ compounds, and plot both the $0 \mathrm{ls}$ binding energy (Figure 6) and the $\mathrm{C}$ 1s binding energy (Figure 7) of the CO ligands against the weighted-average CO force constants. The correlation is equally good for either ligand atom. 18 When one 
considers the variety of transition elements, metal coordination numbers, and structurally-different ligands included in this series of compounds, the correlations for both oxygen and carbon are indeed remarkable.

Graham $^{15}$ has proposed scales of relative $\sigma$ - and $\pi$-acceptor character for a large number of 1 igands based on the differences in the cis and trans $\mathrm{CO}$ force constants in $\mathrm{Lm}(\mathrm{CO})_{5}$ compounds. Table IV lists Graham's $\sigma$ and $\pi$ parameters for ligands in some of the compounds we have studied. He calculated his parameters based on the following relationships:

$$
\begin{aligned}
& \Delta k_{\text {cis }}=\sigma+\pi \\
& \Delta k_{\text {trans }}=\sigma+2 \pi
\end{aligned}
$$

We can re-express our $E_{B}$ vs. $k_{a v g}^{C O}$ correlations in terms of the relative amounts of 0 -acceptor ability and $\pi$-acceptor ability of $L$ required to describe the binding energy. Since

$$
\Delta k_{\text {avg }}^{C O}=0.20 \Delta k_{\text {trans }}+0.80 \Delta k_{c i s} \text {, }
$$

one substitutes Eqs. 2 and 3 into Eq. 4 to obtain

$$
\Delta k_{\text {avg }}^{C O}=2.2(0.450+0.55 \pi) \text {. }
$$

Consequently, a simple rescaling of the abscissa allows one to express binding energy in terms of $\sigma$ and $\pi$ parameters. This is 111 ustrated for the case of manganese in figure 5. It is interesting that the manganese (or carbon, or oxygen) binding energy depends approximately equally 19 upon the $\sigma$ - and the $\pi$-acceptor abilities of the ligands $L$, assuming that Graham's definitions of $\sigma$ and $\pi$ are correct. This suggests that these binding energies are a good measure of the relative total electronegativity $(\sigma+\pi)$ of the ligands $L$. 


\section{Shake up Satellite Structure}

In many XPS spectra the primary photoline is accompanied by a number of high-binding-energy satellite lines which can be ascribed to electron shake-up. ${ }^{9,20}$ Shake-up is a multi-electron process involving the ejection of a core electron and the simultaneous excitation of a valence electron. Core electrons ejected from molecules undergoing this twoelectron process will have less kinetic energy and, therefore, a higher binding energy than those from molecules involved in a one-electron process. In most transition metal complexes shake-up satellites are observed only on the metal levels. However, metal carbonyls are one of the few classes of compounds to exhibit shake-up in the ligand core level spectra as well. Shake-up structure in spectra of metal carbonyls has been studied in the solid state ${ }^{2,21-24}$ and in the gas phase, 2,25 including compounds of the type $\operatorname{LMn}(\mathrm{CO})_{5}$.

We also have observed intense shake-up satellites on the ligand leveis of $L / m(C O)_{5}$ compounds. Figures 8 and $S$ show the $C$ is and 0 is regions of $\mathrm{HMn}(\mathrm{CO})_{5}$. A single intense shake-up band $\left(I_{s} / I_{p}=20-30 \%\right)$ is observed $25.8 \mathrm{eV}$ from the main photoline in both the carbon and oxygen spectra. This band has been fit to a single Gaussian curve, and spectral parameters for $H M_{n}\left(\mathrm{CO}_{5}\right.$ as well as other $L M_{n}\left(\mathrm{CO}_{5}\right.$ compounds are given in Table $V$. The energy difference $\left(\Delta E_{s}\right)$ between the shake-up band and the primary photoline varies from 5.2 to $5.8 \mathrm{eV}$ for the $\mathrm{C}$ is and 5.1 to 5.8 eV for the 015 , yet no trend can be recognized which shows any chemical significance. The carbon shake-up is more intense than the oxygen shakeup--the relative intensities centering around $28 \%$ for carbon and $20 \%$ for oxygen. There does not appear to be any statistical significance to 
differences in carbon or oxygen shake-up intensity between compounds. Bancroft et al, ${ }^{25}$ studied shake-up satellites in the core levels of $M(C O)_{6}(M=C r, M o, W)$. They observed intense (20-30\%) lines shifted 5-6 eV from the carbon and oxygen primary photolines which they assigned to a $2 t_{2 g}+3 t_{3 g}$ electronic transition. This is a metal-to-ligand charge transfer transition involving the metal $d \pi$ orbitals and the $\pi^{*}$ orbitals of the CO ligands. The shake-up bands we observe probably involve the same metal-to-ligand charge transfer process. Under $C_{4 v}$ symmetry the $t_{2 g}$ representation breaks down to $b_{2}$ and $e$. Therefore the transitions $7 e\left(d_{x z}, d_{y z}\right)+10 e\left(\pi^{*} C_{c i s}\right)$ and $7 e\left(d_{x z}, d_{y z}\right)+9 e\left(\pi^{*} C 0_{\text {trans }}\right)$ along with $2 b_{2}\left(d_{x y}\right)+a b_{2}\left(\pi * C O_{c i s}\right)$ are probably responsible for most of the intensity in the carbon and oxygen shake-up bands we observe.

To a first approximation $\Delta E_{S}$ should be equal to the energy of the corresponding electronic transition in the neutral molecule measured by UV spectroscopy. In the case of $\operatorname{LMn}(\mathrm{CO})_{5}$ compounds whose electronic spectra haye been reported, 26,27 there is disagreement in the assignment of the observed spectral bands. However, the average energies of the UV charge-transfer transitions for some compounds in Table $V$ are roughly similar to $\Delta E_{S}$. In theory $\Delta E_{S}$ should be less than the energy of the neutral molecule excitation ${ }^{28}$ since the $\pi^{*} \mathrm{CO}$ orbitals will relax more than the dis orbitals upen core ionization of carbon or oxygen. Orbital relaxation may also explain the different intensities of the carbon and oxygen shake-up lines. 29

Experimental Section

Standard vacuum line and inert-atmosphere techniques were utilized in the preparation and handling of air-sensitive compounds. Infrared 
spectra were recorded for cyclohexane solutions. Melting points were determined in capillaries sealed under nitrogen. Dimanganese decacarbonyl (Strem) was used as a starting material for most of the derivatives; the purity of $\mathrm{Mn}_{2}(\mathrm{CO})_{10}$ was verified by comparing its infrared spectrum with one in the literature. Manganese pentacarbonyl iodide was prepared by the addition of $\mathrm{I}_{2}$ to a solution of $\mathrm{NaMn}(\mathrm{CO})_{5}$ in THF at room temperature. After removal of the solvent, the residue was placed on a vacuum line, and red-orange crystals condensed in a $0^{\circ}$ trap. The infrared spectrum of $\mathrm{IMn}(\mathrm{CO})_{5}$ agreed with the literature. ${ }^{30}$ Manganese pentacarbonyl chloride was prepared by the method of Abel and Wilkinson. ${ }^{31}$ Many attempts were made to characterize this compound by its infrared spectrum in cyclohexane soiution, ${ }^{30}$ but peaks attributable to $\mathrm{Mn}_{2}\left(\mathrm{CO}_{8} \mathrm{Cl}_{2}\right.$ were always present, along with the bands from the monomer. This is consistent with the findings of Bamford, et al ${ }^{32}$ that $\mathrm{CIMn}(\mathrm{CO})_{5}$ easily undergoes a thermal interconversion to $\mathrm{Mn}_{2}(\mathrm{CO})_{8} \mathrm{Cl}_{2}$ in solution through the loss of $\mathrm{C} 0$. Consequently, the $\mathrm{ClMn}(\mathrm{CO})_{5}$ sample was characterized by means of its mass spectrum, 33,34 from which any sign of $\mathrm{Mn}_{2}(\mathrm{CO})_{8} \mathrm{Cl}_{2}$ impurity was absent. The $\mathrm{BrMn}(\mathrm{CO})_{5}$ (Strem) was identified by its IR spectrum. ${ }^{30}$ Trichlorosilyl manganese pentacarbonyl and $\mathrm{F}_{3} \operatorname{SiMn}(\mathrm{CO})_{5}$, were prepared and characterized as described in the literature. ${ }^{35,36}$ The derivatives $\mathrm{CH}_{3} \mathrm{COMn}(\mathrm{CO})_{5}$ and $\mathrm{CF}_{3} \mathrm{COMn}(\mathrm{CO})_{5}$ were prepared by the $r$ action of acetyl chloride or crifluoroacetic anhydride with $\mathrm{NaMn}(\mathrm{CO})_{5} / \mathrm{THF}$; their melting points agreed with the literature. ${ }^{37,38}$ Methyl manganese pentacarbonyl and $\mathrm{CF}_{3} \mathrm{Mn}(\mathrm{CO})_{5}$ were made by the decarbonylation of the corresponding acety 1 derivatives. ${ }^{37,38}$ The $\left(\mathrm{CH}_{3}\right)_{3} \mathrm{SnMn}(\mathrm{CO})_{5}$ was prepared and characterized as described in the literature. ${ }^{39}$ Manganese 
pentacarbonyl hydride was prepared according to the literature; ${ }^{38}$ it was redistilled just prior to the XPS measurement.

\section{$\underline{X-R a y}$ Photoelectron Spectra}

The gas-phase XPS spectra were measured on a GCA/McPherson ESCA 36 Photoelectron Spectrometer ${ }^{40}$ using $M g K_{\alpha} X$-rays (1253.6 eV). Sample vapors were metered into the irradiation chamber through a glass-andstainless steel manifold. For samples of low-volatility, a speciallydesigned stainless-steel inlet system was used such that sample vapors are delivered to the chamber through a short length of $2 \mathrm{~cm}$ diameter tubing. Sample spectra were calibrated with runs of reference gas levels of known binding energies: ${ }^{41} \mathrm{Ne}$ is $\left(E_{B}=870.37 \mathrm{eV}\right), \mathrm{N}_{2}, \mathrm{~N} 1 \mathrm{~s}$ $\left(E_{B}=409.93 \mathrm{eV}\right), \operatorname{Ar} 2 p_{3 / 2}\left(E_{B}=248.62 \mathrm{eV}\right), \operatorname{Ne} 2 \mathrm{~s}\left(E_{B}=48.47 \mathrm{eV}\right)$. The references used for a given compound are indicated in Table $I$. Binding energies vere determined by a least-squares fitting of the data to either Gaussian or Lorentzian line shapes. The reported binding energies correspond to absolute free-molecule ionization potentials. 
Table I. Core Binding Energies of $\mathrm{Mn}(\mathrm{CO})_{5}$ Moiety.

\begin{tabular}{|c|c|c|c|c|c|c|}
\hline \multirow[b]{2}{*}{ Compound } & \multicolumn{2}{|c|}{$\operatorname{Mn} 2 \mathrm{p}_{3 / 2}$} & \multicolumn{2}{|c|}{ C Is } & \multicolumn{2}{|c|}{$01 \mathrm{~s}$} \\
\hline & $E_{B}, e V$ & FWHM, eV & $E_{B}, e V$ & FWHM, eV & $E_{B}=\mathrm{eV}$ & FWHM, eV \\
\hline$\left(\mathrm{CH}_{3}\right)_{3} \mathrm{SnMn}(\mathrm{CO})_{5}^{d}$ & $647.0(1)^{c}$ & \multicolumn{5}{|l|}{$1.3(1)$} \\
\hline $\mathrm{Mn}_{2}(\mathrm{CO})_{10}{ }^{\mathrm{a}}$ & $647.01(3)$ & $1.02(9)$ & $293.28(3)$ & $1.12(6)$ & $539.57(7)$ & $1.44(4)$ \\
\hline $\mathrm{CH}_{3} \mathrm{COMn}(\mathrm{CO})_{5}{ }^{\mathrm{d}}$ & $647.2(1)$ & $1.2(1)$ & $293.5(1)$ & $1.5(1)$ & $539.9(1)$ & $1.5(1)$ \\
\hline $\mathrm{CH}_{3} \mathrm{Mn}(\mathrm{CO})_{5}{ }^{\mathrm{a}}$ & $647.30(5)$ & $1.1(1)$ & $293.62(7)$ & $1.22(7)$ & $539.91(7)$ & $1.51(8)$ \\
\hline $\mathrm{HMn}(\mathrm{CO})_{5}{ }^{\mathrm{a}}$ & $647.46(4)$ & $1.1(1)$ & $293.80(4)$ & $1.2(1)$ & $539.95(3)$ & $1.46(8)$ \\
\hline $\operatorname{IMn}(\mathrm{CO})_{5} \mathbf{b}$ & $647.73(3)$ & $1.0(1)$ & $294.05(3)$ & $1.29(7)$ & $540.30(3)$ & $1.61(8)$ \\
\hline $\mathrm{Cl}_{3} \operatorname{SiMn}(\mathrm{CO})_{5}{ }^{b}$ & $647.84(4)$ & $1.0(1)$ & $294.12(3)$ & $1.22(8)$ & $540.37(3)$ & $1.42(7)$ \\
\hline $\mathrm{CF}_{3} \mathrm{COMn}(\mathrm{CO})_{5}{ }^{\mathrm{a}}$ & $647.90(5)$ & $1.0(1)$ & $294.22(5)$ & $1.15(9)$ & $540.54(3)$ & $1.51(6)$ \\
\hline $\operatorname{BrMn}(\mathrm{CO})_{5}{ }^{\mathrm{b}}$ & $647.94(3)$ & $0.91(9)$ & $294.14(4)$ & $1.33(9)$ & $540.43(3)$ & $1.61(7)$ \\
\hline $\operatorname{cimn}_{(\mathrm{CO})}{ }_{5}^{\mathrm{b}}$ & $647.98(3)$ & $1.1(1)$ & $294.16(4)$ & $1.28(9)$ & $540.49(3)$ & $1.55(8)$ \\
\hline $\mathrm{CF}_{3} \mathrm{Mn}(\mathrm{CO})_{5}{ }^{\mathrm{a}}$ & $648.09(2)$ & $1.05(7)$ & $294.40(2)$ & $1.24(4)$ & $540.67(2)$ & $1.52(4)$ \\
\hline $\mathrm{F}_{3} \operatorname{SiMn}(\mathrm{CO})_{5}{ }^{\mathrm{a}}$ & $648.12(3)$ & $1.01(8)$ & $294.43(3)$ & $1.22(5)$ & $540.59(3)$ & $1.45(6)$ \\
\hline $\begin{array}{l}\text { a Binding energies } \\
\text { bBinding energies } \\
\text { c The uncertainty } \\
\text { squares fit) is } \\
\text { appear in S.C. Av } \\
\text { Avanzino and W.L. }\end{array}$ & $\begin{array}{l}\text { se compo } \\
\text { se compc } \\
\text { ast digi } \\
\text { parenth } \\
\text { nd W.L. } \\
\text { J. Am. }\end{array}$ & $\begin{array}{l}\text { are C: } \\
\text { are } \\
\text { stimate } \\
\text { ally. } \\
\text { Soc., }\end{array}$ & $\begin{array}{l}\text { against } t \\
\text { against } t \\
\text { e the sta } \\
\text { these co } \\
\text { pectrosc. } \\
(1976) .\end{array}$ & $\begin{array}{l}\text { Ne is, N } \\
\text { Ne is, N } \\
\text { rd devia } \\
\text { unds wer } \\
\text { lat. Phe }\end{array}$ & $\begin{array}{l}\text { and } \mathrm{N}_{2} \mathrm{~N} 1 \\
\text {, and } \mathrm{Ar} 2 \\
\text { etermined } \\
\text { rmined pre } \\
\underline{8}, 15,197\end{array}$ & $\begin{array}{l}\text { nes. } \\
\text { lines. } \\
\text { he least- } \\
\text { is ly and } \\
\text { d S.C. }\end{array}$ \\
\hline
\end{tabular}


Table II. Ligand Core Binding Energies.

\begin{tabular}{|c|c|}
\hline Compound & Core binding energies and linewidths, $\epsilon v^{a}$ \\
\hline $\mathrm{CH}_{3} \mathrm{COMn}(\mathrm{CO})_{5}$ & C Is $(j \mathrm{C}=0) 292.2(3), 1.8(3) ;\left(-\mathrm{CH}_{3}\right) 290.5(1), 1.3(3) ; 0$ 1s $537.2(1), 1.0(1)$ \\
\hline $\mathrm{CH}_{3} \mathrm{Mn}(\mathrm{CO})_{5}$ & C $1 \mathrm{~s} 289.5(1), 1.5(3)$ \\
\hline $\operatorname{IMn}(\mathrm{CO})_{5}$ & I $3 d_{5 / 2} 625.27(3), 1.27(7)$ \\
\hline $\mathrm{Cl}_{3} \operatorname{Simn}(\mathrm{CO})_{5}$ & C1 $2 \mathrm{p}_{3 / 2} 205.64(4), 1.31(7) ; \mathrm{Cl} 2 \mathrm{p}_{1 / 2} 207.28(6), 1.31(7)$; Si $2 \mathrm{p} 108.38(4)^{\mathrm{b}} 1.36(9)$ \\
\hline $\mathrm{CF}_{3} \mathrm{COMn}(\mathrm{CO})_{5}$ & $\begin{array}{l}\text { C ls }(i C=0) 293.1(i), 1.1(2) ;\left(-C F_{3}\right) 297.9(1), 1.4(2) ; 0 \text { 1s } 538.21(6), 1.3(2) \\
F \text { is } 694.13(3), 1.74(8)\end{array}$ \\
\hline $\operatorname{BrHn}(\mathrm{CO})_{5}$ & $\operatorname{Br} 3 d_{5 / 2} 74.30(3), 1.27(8) ; B r 3 d_{3 / 2} 75.39(3), 1.27(8)$ \\
\hline $\mathrm{ClMn}_{(\mathrm{CO})_{5}}$ & $C 12 p_{3 / 2} 203.84(3), 1.16(7) ; C 12 p_{1 / 2} 205.43(7), 1.16(7)$ \\
\hline $\mathrm{CF}_{3} \mathrm{Mn}(\mathrm{CO})_{5}$ & C is $296.48(4), 1.14(9)$; F 1s $692.98(4), 1.78(9)$ \\
\hline $\mathrm{F}_{3} \operatorname{SiMn}(\mathrm{CO})_{5}$ & F ls $692.86(3), 1.46(6)$; Si 2p $109.0(1),{ }^{b} 1.3(2)$ \\
\hline
\end{tabular}

${ }^{\text {a }}$ The uncertainty in the last digit (estimated as twice the standard deviation determined by the leastsquares fit) is indicated parenthetically. Binding energy calibrations are as indicated in Table 1.

buresolved spin-orbit doublet fit to one peak. 
Table III. Elec tronic Structure Data for $\mathrm{LMn}(\mathrm{CO})_{5}$ Compounds.

\begin{tabular}{|c|c|c|c|c|}
\hline$\Delta E_{B}(M n$ & $\left.2 p_{3 / 2}\right), e v^{a}$ & $I P, e V^{b}$ & $x_{L}^{c}$ & $\begin{array}{l}\text { Total Orbital } \\
\text { Occupation } \\
\text { for Mangangese, } \\
\text { electrons }\end{array}$ \\
\hline $\mathrm{CH}_{3} \mathrm{Mn}(\mathrm{CO})_{5}$ & 0.0 & 8.67 & 2.3 & \\
\hline $\mathrm{HMn}(\mathrm{CO})_{5}$ & 0.16 & 9.53 & 2.1 & 7.420 \\
\hline $\operatorname{IMn}(\mathrm{CO})_{5}$ & 0.43 & 9.89 & 2.5 & 7.424 \\
\hline $\mathrm{CF}_{3} \mathrm{COMn}(\mathrm{CO})_{5}$ & 0.60 & 9.0 & & \\
\hline $\operatorname{BrHn}(\mathrm{CO})_{5}$ & 0.64 & 10.32 & 2.8 & 7.385 \\
\hline $\mathrm{ClMn}(\mathrm{CO})_{5}$ & 0.68 & 10.72 & 3.0 & 7.312 \\
\hline $\mathrm{CF}_{3} \operatorname{Mn}(\mathrm{CO})_{5}$ & 0.79 & 9.57 & 3.3 & \\
\hline
\end{tabular}

aFrom Table I.

$b_{V a l u e s}$ reported are the degeneracy-weighted averages of the $6 e$ $\left(d_{x z}, d_{y z}\right)$ and the $2 b_{2}\left(d_{x y}\right)$ levels. The data are taken from Refs. 7 and 8 ; where two values for the same compound are available, the average is reported.

CAtomic and group electronegativity values are taken from Refs. 11 and 12.

$d_{\text {Values are the sum of the calculated orbital occupations for all }}$ manganese orbitals taken from Ref. 3. 
Table IV. Force Constants and Graham's o and $\pi$ Parameters for $L \operatorname{Ln}(\mathrm{CO})_{5}$
Compounds.

\begin{tabular}{|c|c|c|c|}
\hline Compound & $k_{\text {avg }}^{C O}, m d y n / A^{b}$ & $\sigma$ & $\pi$ \\
\hline$\left(\mathrm{CH}_{3}\right)_{3} \mathrm{SnNn}(\mathrm{CO})_{5}$ & 16.45 & -0.84 & 0.51 \\
\hline $\min _{2}(\mathrm{CO})_{10}$ & 16.38 & -0.89 & 0.49 \\
\hline $\mathrm{CH}_{3} \mathrm{Mn}(\mathrm{CO})_{5}$ & 16.68 & 0.0 & 0.0 \\
\hline $\operatorname{HMn}(\mathrm{CO})_{5}$ & 16.83 & -0.09 & 0.20 \\
\hline $\operatorname{IMn}(\mathrm{CO})_{5}$ & 17.08 & 0.73 & -0.27 \\
\hline $\mathrm{Cl}_{3} \mathrm{SiMn}(\mathrm{CO})_{5}$ & 17.11 & -0.06 & 0.41 \\
\hline $\mathrm{CF}_{3} \mathrm{COMn}(\mathrm{CO})_{5}$ & 17.11 & 0.28 & 0.13 \\
\hline $\mathrm{BrMn}(\mathrm{CO})_{5}$ & 17.18 & 1.03 & -0.44 \\
\hline $\mathrm{ClMn}(\mathrm{CO})_{5}$ & 17.24 & 1.25 & -0.57 \\
\hline $\mathrm{CF}_{3} \mathrm{Mn}(\mathrm{CO})_{5}$ & 17.19 & 0.56 & -0.04 \\
\hline
\end{tabular}


$\mathrm{Mn}_{2}(\mathrm{CO})_{10}$ are taken from Ref. 15. For $\mathrm{Mn}_{2}(\mathrm{CO})_{10}$ the force constants from H. Haas and R.K. Sheline, J. Chem. Phys., 47, 2996 (1967) were used to calculate $\sigma$ and $\pi$ according to the method of Ref. 15. ${ }^{b}$ The values of $k_{\text {avg }}^{C O}$ are calculated from the ralation $k_{\text {avg }}^{C O}=1 / 5 k_{\text {trans }}+$ $4 / 5 k_{\text {cis. }}$ 
Table V. Relative Energies and Relative Intensities of Shake-up Satellites.

\begin{tabular}{|c|c|c|c|c|c|}
\hline \multirow{2}{*}{ Compound } & \multicolumn{2}{|c|}{ C 15} & \multicolumn{2}{|c|}{015} & \multirow{2}{*}{$\begin{array}{l}\text { Average } \\
M \rightarrow L C T \\
\text { Energy, ev }{ }^{d}\end{array}$} \\
\hline & $\Delta E_{S}, e v^{a}$ & $I_{S} / I_{p}, q_{s}^{b}$ & $\Delta E_{S}, e V$ & $\mathrm{I}_{S} / \mathrm{I}_{\mathrm{P}}, *$ & \\
\hline $\mathrm{Mn}_{2}(\mathrm{CO})_{10}$ & $5.47(19)^{\mathrm{C}}$ & $22(5)$ & $5.37(10)$ & $23(3)$ & \\
\hline $\mathrm{CH}_{3} \mathrm{Mn}(\mathrm{CO})_{5}$ & $5.42(7)$ & $27(3)$ & $5.50(6)$ & $19(2)$ & 6.01 \\
\hline $\mathrm{HMn}(\mathrm{CO})_{5}$ & $5.75(8)$ & $24(3)$ & $5.82(8)$ & $18(2)$ & 6.04 \\
\hline $\operatorname{IMn}(\mathrm{CO})_{5}$ & $5.36(8)$ & $30(4)$ & $5.52(7)$ & $19(2)$ & 6.10 \\
\hline $\mathrm{CF}_{3} \mathrm{COMn}(\mathrm{CO})_{5}$ & $\begin{array}{l}5.32(12) \\
5.20(14)\end{array}$ & $\begin{array}{l}32(\text { forced }) \\
32(\text { forced })\end{array}$ & $5.11(10)$ & $21(4)$ & \\
\hline $\operatorname{BrMn}(\mathrm{CO})_{5}$ & $5.47(9)$ & $30(5)$ & $5.51(6)$ & $20(2)$ & 6.12 \\
\hline $\mathrm{CF}_{3} \mathrm{Mn}(\mathrm{CO})_{5}$ & $5.29(\overline{6})$ & $32(4)$ & $5.30(6)$ & $21(2)$ & 5.97 \\
\hline $\mathrm{F}_{3} \mathrm{SiMn}(\mathrm{CO})_{5}$ & $5.54(7)$ & $27(3)$ & $5.70(6)$ & $18(2)$ & \\
\hline
\end{tabular}

$M \rightarrow L C T$

Energy, ev

${ }^{a}$ Energy difference between the shake-up band and primary photoline.

bintensity of shake-up relative to intensity of photoline.

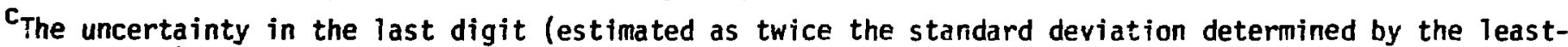
squares fit) is indicated parenthetically.

${ }^{d}$ The average of individual charge-transfer bands resolved in the UV spectrum, each band weighted by its relative intensity. No bands with less than $10 \%$ relative intensity were included. Values taken from Ref. 26. 


\section{Fiqure Captions}

Figure 1. Plot of carbonyl carbon 1 s binding energy vs. manganese $2 p_{3 / 2}$ binding energy for $\mathrm{LMn}(\mathrm{CO})_{5}$ compounds.

Figure 2. Plot of carbonyl oxygen ls binding energy vs. manganese $2 p_{3 / 2}$ binding energy for $\mathrm{LMn}(\mathrm{CO})_{5}$ compounds.

Figure 3. Plot of carbonyl carbon is binding energy vs. the weightedaverage $\mathrm{CO}$ force constants for $\mathrm{LMn}(\mathrm{CO})_{5}$ compounds.

Figure 4. Plot of carbonyl oxygen is binding energy vs. the weightedaverage $\mathrm{CO}$ force constants for $\mathrm{LMn}(\mathrm{CO})_{5}$ compounds.

Figure 5. Plot of manganese $2 p_{3 / 2}$ binding energy vs. the weightedaverage $\mathrm{CO}$ force constants for $\mathrm{LMn}(\mathrm{CO})_{5}$ compounds.

Figure 6. Plot of oxygen ls binding energy for carbonyl complexes vs. the weighted-average $\mathrm{CO}$ force constants.

Figure 7. Plot of carbon 15 binding energy for carbonyl complexes vs. the weighted-average $\mathrm{CO}$ force constants.

Figure 8. The carbon is spectrum of $\operatorname{HMn}(\mathrm{CO})_{5}$.

Figure 9. The oxygen is spectrum of $\mathrm{HMn}(\mathrm{CO})_{5}$. 


\section{References}

1. F.A. Cotton and G. Wilkinson, "Advanced Inorganic Chemistry," 3rd ed., Intersclence, New York, N.Y., 1972, Chapter 22.

2. J.A. Connor, M.B. Hall, I.H. Hillier, W.N.E. Meredith, M. Barber, and Q. Herd, J. Chem. SoC., Faraday Trans. 2, 1677 (1973).

3. R.F. Fenske and R.L. DeKock, Inorg. Chem., 9, 1053 (1970).

4. D.A. Brown and W.J. Chambers, J. Chem. Soc. (A), 2083 (1971).

5. M.B. Hall and R.F. Fenske, Inorg. Chem., 11, 768 (1972).

6. M.B. Hall and R.F. Fenske, Inorg. Chem., 11, 1619 (1972).

7. S. Evans, J.C. Green, M.L.H. Green, A.F. Orchard, and D.W. Turner, Discuss. Faraday Soc., 47, 112 (1969).

8. D.L. Lichtenberger, A.C. Sarapu, and R.F. Fenske, Inorg. Chem., 12. 702 (1373).

9. K. Siegbahn, et al, "ESCA Applied to Free Molecules," NorthHolland Publishing Co., Amsterdam, and American Elsevier, New York, N.Y., 1969.

10. The values of $k$ were calculated from the relation $k=14.4 / r_{\text {cov }}$ using covalent rodii consistent with the $\mathrm{Mn}-\mathrm{C}$ and $\mathrm{C}-\mathrm{O}$ bond distances in $\operatorname{LMn}(\mathrm{CO})_{5}$ compounds.

11. P.R. Wells, in "Progress in Physical Organic Chemistry," Vol. 6, A. Streitwieser, Jr., and R.W. Taft, Eds., Wiley (Interscience), New York, N.Y., 1968, p. 111.

12. L. Pauling, "The Nature of the Chemical Bond," 2nd Ed., Cornell University Press, Ithaca, New York, 1948.

13. S.C. Avanzino and W.L. Jolly, J. Am. Chem. Soc., 98, 6505 (1976).

14. S.C. Avanzino, W.L. Jolly, P.-A. Malmquist, and K. Siegbahn, Inorg. Chem., 17, 489 (1978).

15. W.A.G. Graham, Inorg, Chem., I, 315 (1968).

16. Calculated by the relation $k_{a v g}^{C O}=1 / 5 k_{\text {trans }}+4 / 5 k_{\text {cis }}$.

17. W.L. Jolly, S.C. Avanzino, and R.R. Rietz, Inorg. Chem., 16, 964 (1977). 
18. The least-squares line in Figure 6 corresponds to the equation $E_{B}(015)=1.03 k_{C O}+522.71$. The correlation coefficient is 0.968 . The least-squares 1 ine in Figure 7 corresponds to the equation $E_{B}(C$ is $)=1.14 k_{C O}+274.60$. The correlation coefficient is 0.967 .

19. As show in the text, the proportion of $\sigma$ and $\pi$ that is plotted, i.e., $0.450+0.55 \pi$, is predetermined by the quantities we have chosen to correlate. He attempted to optimize the relative amounts of $\sigma$ and $\pi$ for the correlations with each of the three elements, but found that in each case the improvement in the fit as the result of including an additional parameter was not statistically significant.

20. M.A. Brisk and A.D. Baker. J. Electron Spectrosc. Relat. Phenom., I. 197 (1975).

21. M. Barber, J.A. Connor, and I.H. H1llier, Chem. Phys. Lett., 9 , 570 (1971).

22. M. Barber, J.A. Connor, M.F. Guest, M.B. Hall, I.H. Hillier, and W.N.E. Meredith, Faraday Discuss. Chem. Soc., 54, 219 (1972).

23. S. Pignataro, 2. Naturforsch., A, 27, 816 (1972).

24. S. Pignataro, A. Foffoni, and C. Distefano, Chem. Phys. Lett., 20, 350 (1973).

25. G.M. Bancroft, B.D. Boyd, and D.K. Creber, Inorg. Chem., 17, 1008 (1978).

26. G.B. Blakney and H.F. Allen, Inorg. Chem., 10, 2763 (1971).

27. R.A.N. Mclean, J. Chem. Soc., Dalton Trans., 1568 (1974).

28. H. Basch, Chem. Phys. Lett., 37, 447 (1976).

29. H.L. Jolly, Topics in Current Chemistry, 1, 149 (1977).

30. H.D. Kaesz, R. Bau, D. Hendrickson, and J.M. Smith, J. Am. Chem. SoC., 89, 2844 (1967).

31. E.H. Abel and G. Hilkinson, J. Chem. Soc., 1501 (1959).

32. C.H. Bamford, J.H. Burley, and M. Coldbeck, J. Chem. Soc., Dalton Trans.. 1846 (1972).

33. K. Edgar, B.F.G. Johnson, J. Lewis, I.G. Millians, and J.M. Wilson, J. Chem. Soc. (A), 379 (1967). 
34. J. Lewis, R.A. Manning, J.R. Miller, and J.M. Wilson, J. Chem. Soc. (A), 1663 (1966).

35. W. Jetz and W.A.G. Graham, J. Am. Chem. Soc., 89, 2773 (1967).

36. R.R. Schrieke and B.0. West, Inorg. Nucl. Chem. Lett., $\underline{5}, 141$ (1969).

37. R.D. Closson, J. Kozikowski, and T.H. Coffield, J. Org. Chem., 22, $598(1957)$.

38. R.B. King, "Organometallic Syntheses," Vol. 1, Academic Press, New York, N.Y., 1965, p. 148.

39. R.E.J. Bichler, M.R. Booth, H.C. Clark, and B.K. Hunter, Inorg. Syn., 12, 60 (1970).

40. Purchased from GCA/McPherson Instrument, 530 Main St., Acton, Massachusetts 01720.

41. G. Johansson, J. Hedman, A. Berndtsson, M. Klasson, and R. Nilsson, J. Electron Spectrosc. Relat. Phenom., 2, 295 (1973). 


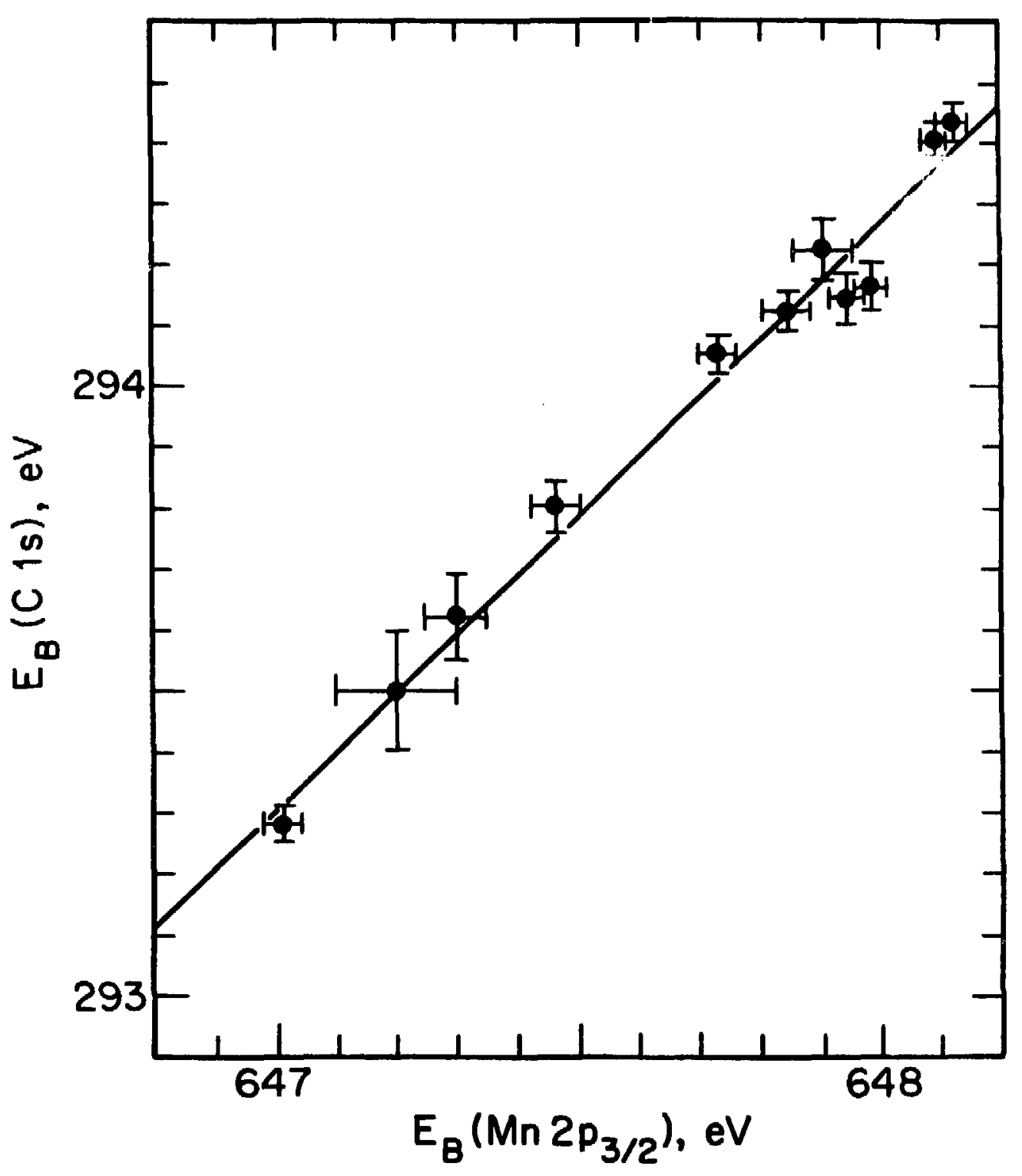


$\Lambda^{\partial}\left(\left(^{2 / \varepsilon_{d}} \mathrm{u} w\right)^{\theta_{\exists}}\right.$

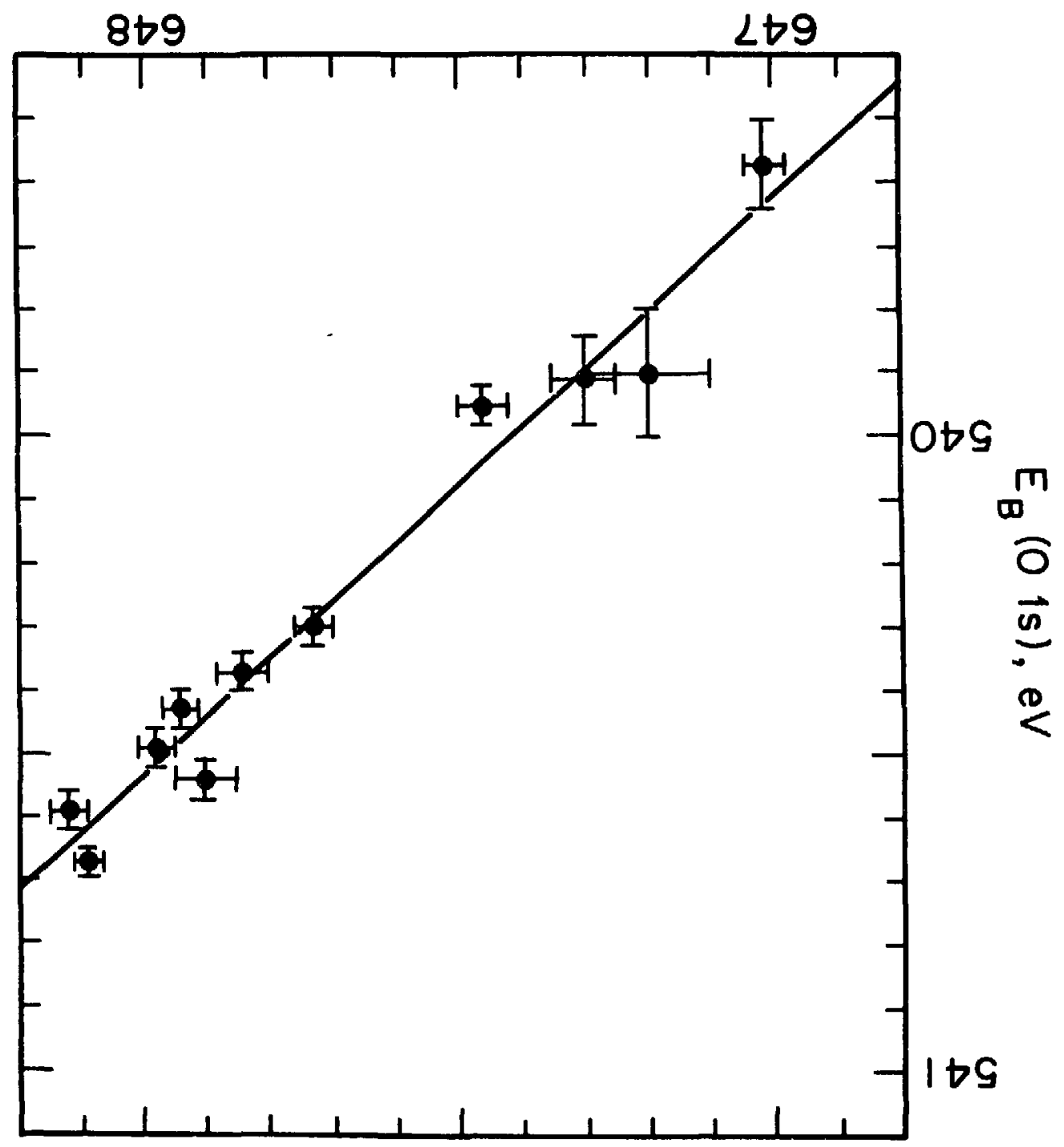




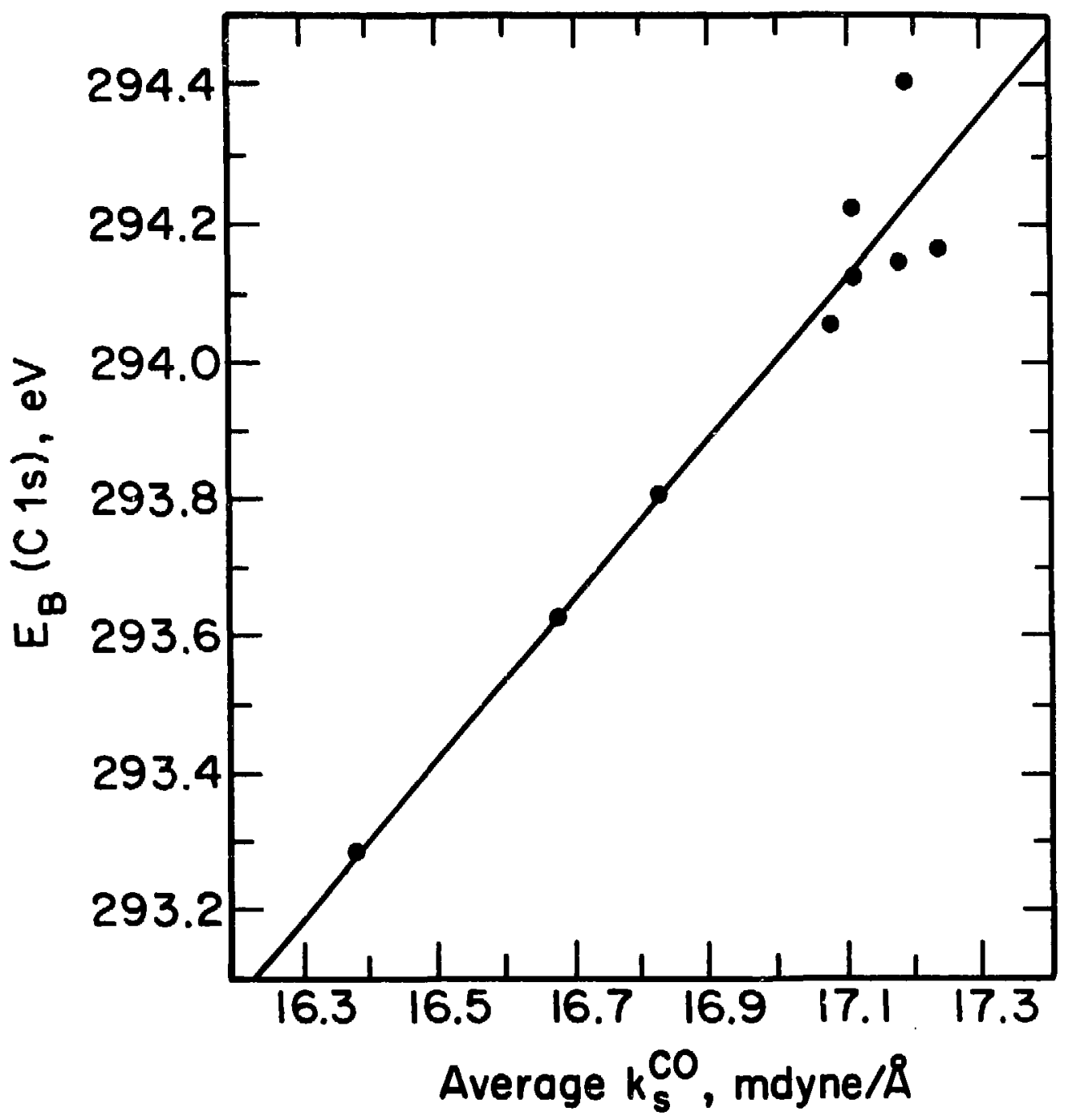




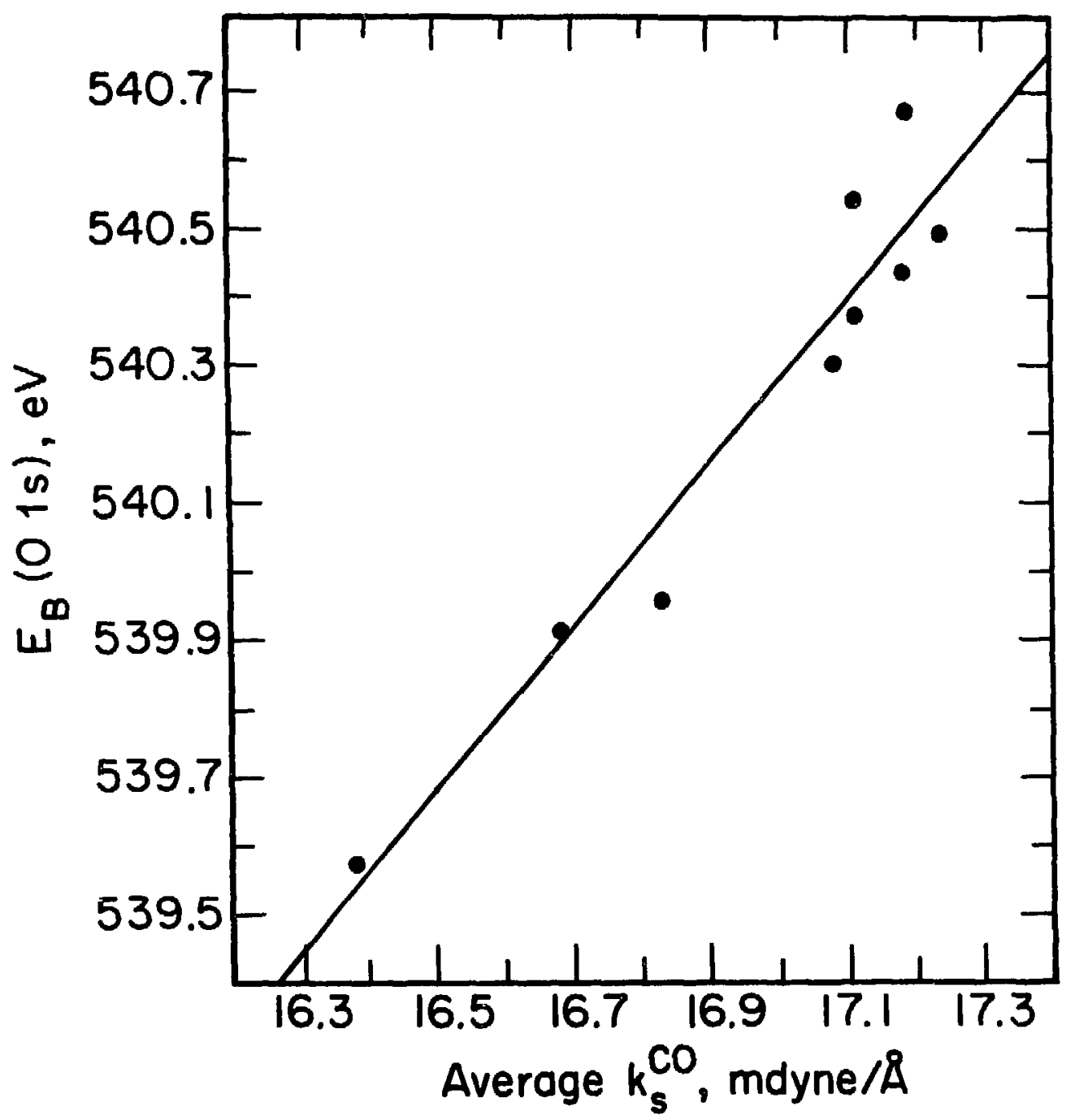


$-49-$

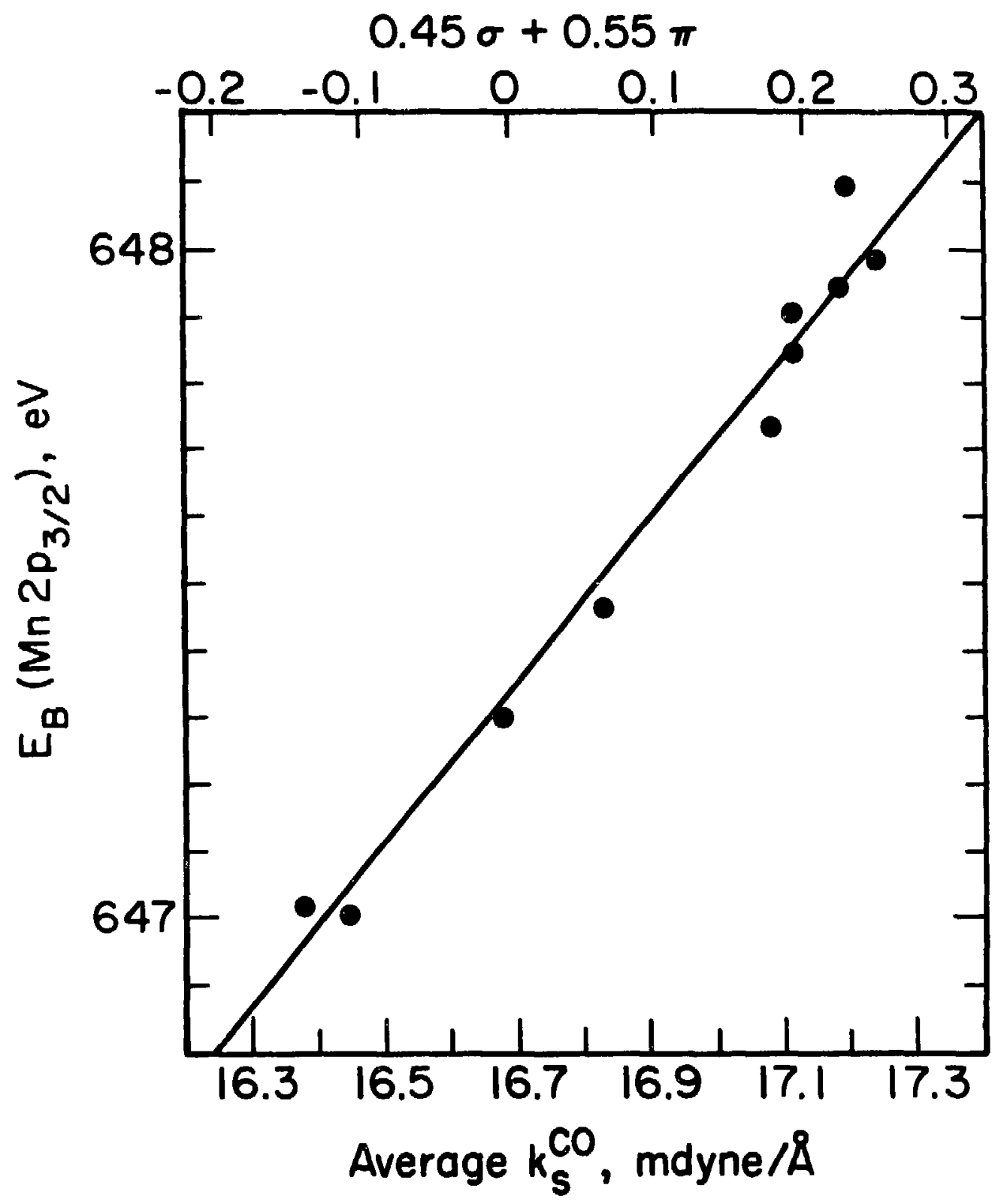




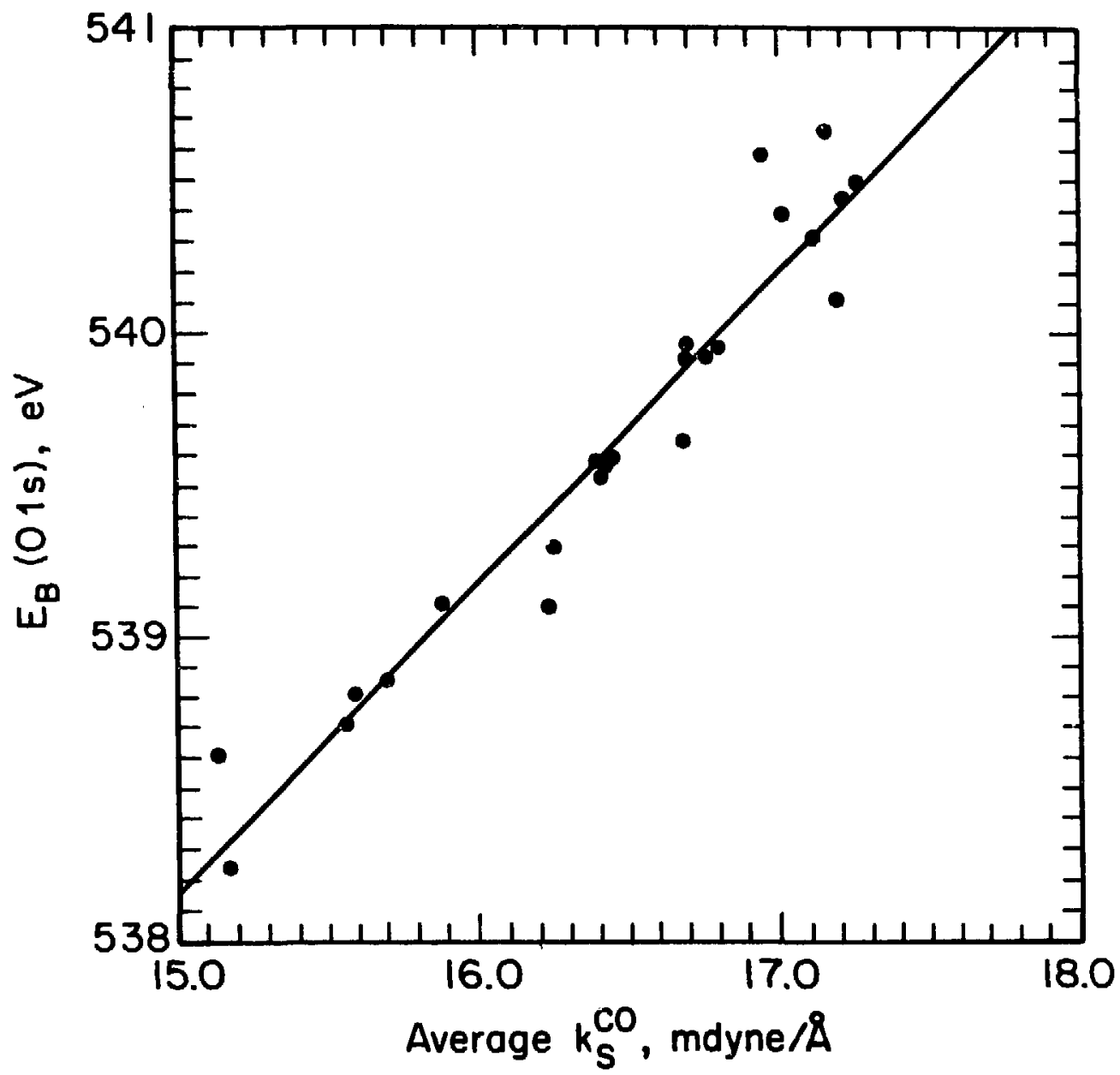







$-52-$

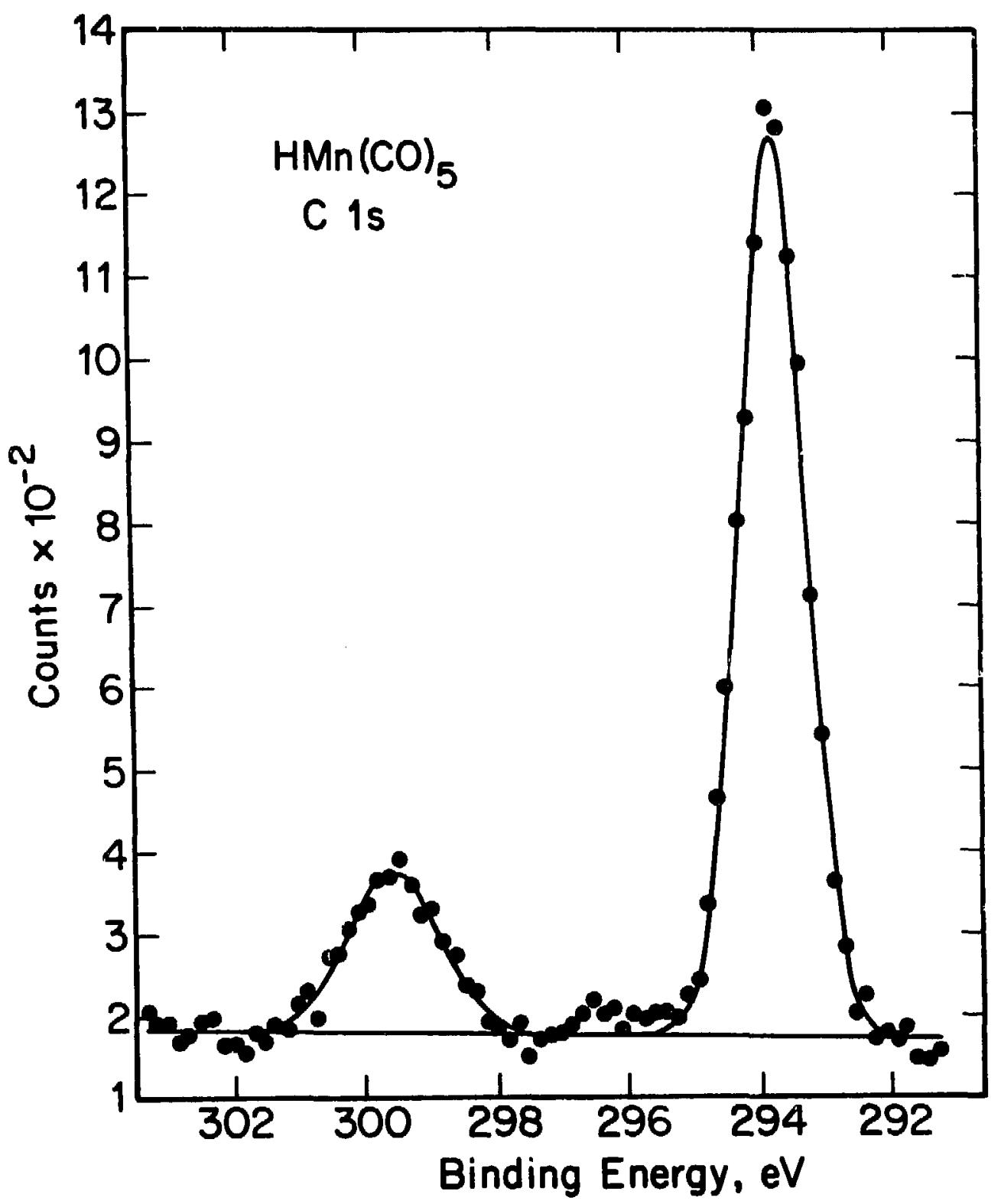


-53-






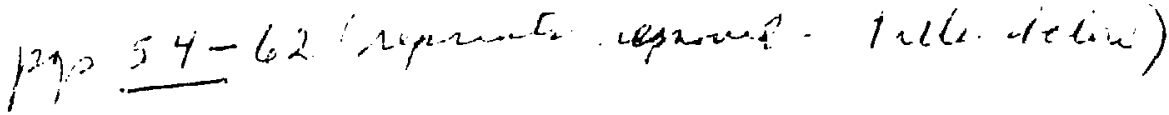

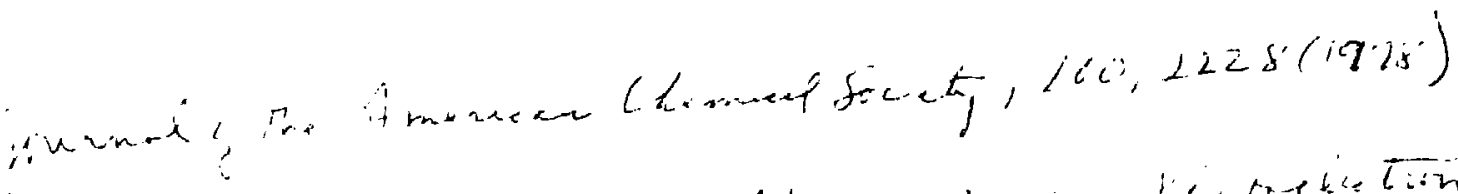

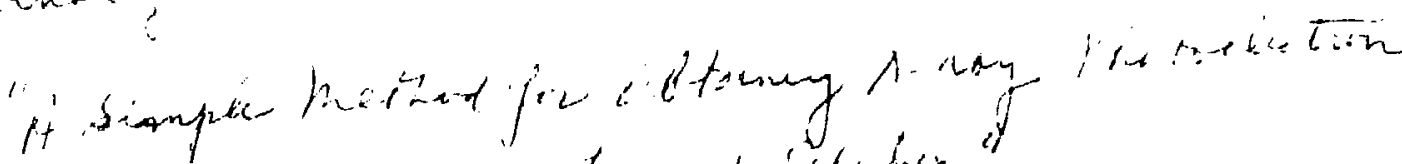

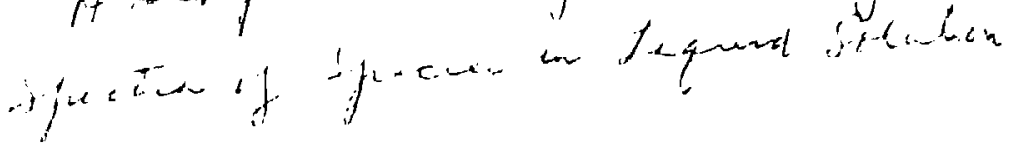

[Reprinted from Inorganic Chemistry, 14, 1595 (1975).] Copyright 1975 by the American Chemical Society and reprinted by permission of the copyright owner.

Evidence for Hyperconjugation from an X-Ray Photoelectron Spectroscopic Study of Isoelectronic Compounds

STEVEN C AVANZINO, WILLIAM L. JOLLY, MARC S LAZARUS. WINFIELD B. PERRY, RIC HARD R RIETZ, and THEODORE F. SCHAAF

[Reprinted from Inorganic Chemistry 16, 2046 (1977)]

Copyright 1977 by the American Chemical Society and reprinted by permission of the copyright owner.

Core Electron Binding Energies of Cyclotriphosphazenes and Cyclotetraphosphazenes S. C AVANZINO,' W. L. JOLLY," T. F. SCHAAF,' and H. R. ALLCOCK' 


\section{The Core Electron Binding Energies of Gaseous Chlorine Monofluoride}

The measurement of the core electron binding energies of chlorine monofluoride by $x$-ray photoelectron spectroscopy was attempted numerous times in the past 5 years by a number of experimenters with results which were not always satisfactory. The first XPS experiment involving CIF was reported by Carroll and Thomas.' Subsequent experiments were conducted by Perry and Jolly. ${ }^{2}$ The poor agreement between these sets of experimental results prompted further studies by Avanzino, Thomas, and Jolly, 3 and Avanzino and Jolly. ${ }^{4}$

chlorine monofluoride ${ }^{5}$ is a gaseous fluorinating agent which reacts vigorously with water, organic substances, and even Teflon. When in contact with metal surfaces, CIF reacts to form a passive metal fluoride film which prevents further attack. In light of its reactive nature, any spectroscopic measurement on CIF must be carefully conducted to prevent interference from impurities. It is likely that the early XPS studies of CIF were carried out using contaminated samples. Carroll and Thomas used commercial CIF but make no reference to a purity check on their sample. Commercial cylinders of CIF often contain substantial amounts of $\mathrm{ClF}_{3}$. Perry may have used a glass vacuum line in handling his ClF sample, which would result in the formation of $\mathrm{SiF}_{4}$. Recent studies $^{3,4}$ were carried out with samples of known composition such that the results were not affected by impurities.

ClF Experiment of Juiy $1976^{3}$

Sample Preparation. The purification and handling of CIF and $F_{2}$ 
were sarried out in an all-metal vacuum line. The infrared spectrum of CIF was measured in a special $7 \mathrm{~cm}$ - pathlength Monel cell with silver chloride windows mounted against Teflon gaskets. In order to determine the purity of the sample, the observed spectrum was compared with literature spectra ${ }^{6-11}$ of $\mathrm{ClF}$ and of the possitle impurities $\mathrm{ClF}_{3}$, $\mathrm{ClO}_{2} \mathrm{~F}, \mathrm{ClO}_{2}, \mathrm{CF}_{4}$, and $\mathrm{SiF}_{4}$. The pure materials were stored in $100 \mathrm{~cm}^{3}$ Monel or copper containers sealed with Whitey valves having Kel-F tipped stems. The vacuum line, storage containers, and IR cell were passivated first with $F_{2}$ then with ClF prior to use.

A sample of ClF from $K \& K$ Laboratories, Hollywood $C A$, was found to contain considerable amounts of chloryl fluoride and silicon tetrafluoride. The $\mathrm{SiF}_{4}$ was chemically removed from the sample by repeated condensation onto activated $\mathrm{KF}$. The $\mathrm{ClF}$ was then separated from the less volatile $\mathrm{ClO}_{2} \mathrm{~F}$ by distillation from the mixture held at $-160^{\circ} \mathrm{C}$. The infrared spectrum of this purified sample was that of pure $\mathrm{ClF}$. (A small band at $21280 \mathrm{~cm}^{-1}$ is attributable to traces of $\mathrm{CF}_{4}$ formed by the reaction of ClF with the Teflon gaskets of the IR cell.) The samples of fluorine and chlorine were purchased from the Matheson Co. $\left(F_{2}, 98.5 \%\right.$ pure; $\mathrm{Cl}_{2}$, Research Grade) and were used without purification.

X-Ray Photoelectron Spectra. The gas-phase XPS spectra were obtained on the cylindrical-mirror electrostatic-focusing spectrometer 12 at Oregon State University, Corvallis, Oregon. Aluminum $K \alpha \not K$-rays $(1486.6 \mathrm{eV})$ were used for all spectra. An all-metal inlet system was used to conduct the sample gases to a stainless-steel irradiation chamber having an aluminum window. Fluorine and ClF were bled through 
the inlet system for 15 minutes prior to the start of each experiment. For the fluorine binding energy measurements a mixture of neon and either $\mathrm{F}_{2}$ of $\mathrm{ClF}$ was introduced into the spectrometer. Data were alternately collected on the $F$ is $l$ ine and the $\mathrm{Ne}{ }^{1} D_{2}$ Auger line ${ }^{13}$ which was used as a reference. For the chlorine binding energy measurements a mixture of argon and either $\mathrm{Cl}_{2} \mathrm{Cr} \mathrm{ClF}$ was introduced, so that the $\mathrm{Cl} 2 \mathrm{~s}$ and $\mathrm{Cl} 2 \mathrm{p}$ lines could be similarly referenced to the $\operatorname{Ar} 2 \mathrm{p}_{3 / 2}$ line, ${ }^{14}$ Binding energies were determined by a least-squares fitting of the data to Gaussian line shapes.

The CIF F ls binding energies were measured using the sample of purified ClF. However, this sample was exhausted before the chlorine binding energies could be measured. An attempt was made to purify a second sample of $\mathrm{CIF}$ at Oregon State University. Efforts were hampered by a lack of acilities, and the purity of this second sample could not be ascertained. Nevertheless, several measurements of both the $\mathrm{Cl} 2 \mathrm{~s}$ and $\mathrm{Cl} 2 \mathrm{p} \mathrm{ClF}$ binding energies were made.

ClF Experiment of August $1978^{4}$

The poor agreement between the $\mathrm{Cl} 2 \mathrm{~s}$ binding energy measurements which were made on a sample of questionable purity at Oregon State University prompted yet another measurement of the $\mathrm{ClF}$ chlorine binding energies.

Sample Preparation. The sample of $\mathrm{CIF}^{15}$ used in the experiment was shown by its infrared spectrum to be free of any chlorine-containing impurities. The spectrum indicated impurities of $\mathrm{CF}_{4}$ and $\mathrm{SiF}_{4}$; however, since only chlorine binding energies were to be remeasured, the sample was used without further purification. 
X-Ray Photoelectron Spectra. The XPS spectra were measured on a GCA/MCPherson ESCA 36 Photoelectron Spectrometer using Mg Ka $x$-rays $(1253.6 \mathrm{eV})$. An all-metal inlet system conducted the ClF to a stainlesssteel gas cell having an aluminum window. The inlet system and gas cell were exposed to a flow of CIF gas at a pressure of 300-400 microns for one hour prior to the start of the experiment. A spectrometer calibration was established both before and after the ClF experiment using three reference points provided by the $\operatorname{Ar} 2 p_{3 / 2}, N_{2} N 1 s$, and $\mathrm{Ne} 1 \mathrm{~s}$ binding energies. ${ }^{14} \mathrm{~A}$ mixture of $\mathrm{CIF}$ and argon was introduced into the spectrometer, and the chlorine hinding energies were directly referenced to the $\operatorname{Ar} 2 \mathrm{p}_{3 / 2}$ line.

The results of the measurements described above, as well as results from earlier measurements, are sumarized in Table $I$. The most accurate binding energies for C.IF have been underlined. In the case of $\mathrm{ClF}$, some large discrepancies exist between the new values and previous measurements. In the case of $\mathrm{Cl}_{2}$ and $\mathrm{F}_{2}$, fairly good agreement. between all values was obtained. The core binding energies for these three molecules are in accord with the expected charge distribution for chlorine monofluoride. Qualitatively, the increased chlorine binding energy of CIF relative to $\mathrm{Cl}_{2}$ indicates that the chlorine of $\mathrm{ClF}$ is positively charged. Likewise, the decrease in fluorine binding energy of ClF vs. $F_{2}$ indicates a negatively charged $C I F$ fluorine atom. One can quantitatively estimate the magnitude of the charges by using the point-charge potential model. ${ }^{16}$ The binding energy shifts are related to the differences in atomic charge between $\mathrm{CIF}$ and the zero-charged elements by the equations 


$$
\begin{aligned}
\Delta E_{B}(F) & =k_{F} Q_{F}+14.4 Q_{C 1} / R_{C 1 F} \\
\Delta E_{B}(C l) & =k_{C l} Q_{C 1}+14.4 Q_{F} / R_{C 1 F} .
\end{aligned}
$$

Here $k$ is the binding energy change per unit change in atomic charge, $Q_{F}$ and $n_{C 1}$ are the atomic charges for $C 1 F\left(Q_{F}=-Q_{C 1}\right)$, and $R_{C I F}$ is the chlorine-fluorine internuclear distance. The value of $k$ can be estimated by several methods. For an atom $X$ of atomic number $Z, k$ is the difference in core binding energy between $x_{z}^{+}$and $x_{z}$. If one uses the equivalent cores approximation, ${ }^{17}$ this binding energy difference can be calculated from valence shell ionization potentials by $E_{B}\left(X_{Z}^{+}\right)-E_{B}\left(X_{Z}\right)=$ $I P\left(X_{Z+1}^{+}\right)-\operatorname{IP}\left(X_{Z}\right)=k\left(x_{Z}\right)$. The potential model indicates that $k$ is inversely proportional to the radius of the valence shell $k\left(x_{2}\right)=$ 14.4(1/R). Here $1 / R$ can be obtained for an $5 p^{3}$ hybridized valence orbital from quantum mechanical calculations by the expression:

$$
1 / R=1 / 4\left(\psi_{n s}\left|r^{-1}\right| \psi_{n s}\right\rangle+3 / 4\left\langle\psi_{n p}\left|r^{-1}\right| \psi_{n p}\right\rangle \text {. }
$$

Alternatively, $I / R$ can be calculated using the experimentally derived covalent radius for an atom.

Using ionization potential data ${ }^{18}$ the appropriate $k$ values for chlorine and fluorine are $14.7 \mathrm{eV} / \mathrm{e}$ and $23.5 \mathrm{eV} / \mathrm{e}$, respectively. These compare well with estimates calculated from covalent radif ${ }^{19}$ $\left\langle k_{C l}=14.5 \mathrm{eV} / \mathrm{e}\right.$ and $\left.k_{F}-22.5 \mathrm{eV} / \mathrm{e}\right)$ but differ significantly from $k$ values calculated from quantum mechanical wavefunctions ${ }^{20} \quad\left(k_{\mathrm{Cl}}=22.3\right.$ $e V / e$ and $\left.k_{F}=37.4 \mathrm{eV} / \mathrm{e}\right)$. However, $\mathrm{k}^{\mathrm{OW}}$ values are applicable to free atoms, whereas $k^{\operatorname{cov}}$ rad $v a l u e s$ may be more appropriate for an atom in a covalently-bound molecule. 
Either Eq. (1) or Eq. (2) can be used to calculate the fluorine and chlorine charges in $C I F$. If Eq. (1) is used the charges range from $-0.18<Q_{F}\left(=-Q_{C l}\right)<-0.09$, depending upon one's choice of $k_{F}$. If Eq. (2) is used the charges are $-0.24<Q_{F}\left(=-Q_{C 1}\right)<-0.10$, in fair agreement with those from Eq. (1). 
Table I. Core electron binding energies.

\begin{tabular}{|c|c|c|c|c|c|c|c|c|c|}
\hline \multirow{2}{*}{ Compound } & \multicolumn{3}{|c|}{ F ls } & \multicolumn{3}{|c|}{$\mathrm{Cl} 2 \mathrm{~s}$} & \multicolumn{3}{|c|}{ C1 $2 p_{3 / 2}$} \\
\hline & $E_{B}, e v^{a}$ & FWHM & Ref. & $E_{B}, e v^{b}$ & FWHM & Ref. & $E_{B}, e v^{b}$ & FWHM & Ref. \\
\hline \multirow[t]{4}{*}{$\mathrm{ClF}$} & $694.16(6)^{c}$ & $1.89(10)$ & 3 & $280.33(8)$ & $2.9(4)$ & 4 & $209.20(4)$ & $1.24(11)$ & 4 \\
\hline & $694.17(6)$ & $1.97(8)$ & 3 & $280.24(8)$ & $2.8(2)$ & 3 & $209.02(10)$ & $2.2(3)$ & 3 \\
\hline & $694.4(1)$ & $1.09(8)$ & 2 & $279.90(16)$ & $2.6(4)$ & 3 & $209.04(8)$ & $2.3(3)$ & 3 \\
\hline & $694.54(5)$ & - & 1 & $279.23(10)$ & -- & 1 & $209.27(4)$ & $1.12(10)$ & 2 \\
\hline \multirow[t]{2}{*}{$F_{2}$} & $696.66(6)$ & $1.55(10)$ & 3 & & & & & & \\
\hline & $696.70(5)$ & - & 1 & & & & & & \\
\hline \multirow[t]{3}{*}{$\mathrm{Cl}_{2}$} & & & & $278.65(8)$ & $3.4(3)$ & 3 & $207.81(4)$ & $1.98(10)$ & 3 \\
\hline & & & & $278.76(8)$ & $2.9(2)$ & 3 & $207.86(4)$ & $1.93(10)$ & 3 \\
\hline & & & & $278.66(10)$ & -- & 1 & $207.81(5)$ & $1.00(7)$ & 2 \\
\hline
\end{tabular}




\section{References}

1. T.X. Carroll and T.D. Thomas, J. Chem. Phys., 60, 2186 (1974).

2. W.L. Jolly and W.B. Perry, Inorg. Chem., 13, 2686 (1974).

3. S.C. Avanzino, T.D. Thomas, and W.L. Jolly, unpublished results, July 1976.

4. S.C. Avanzino and W.L. Jolly, unpublished results, August 1978.

5. G. Brauer, "Handbook of Preparative Inorganic Chemistry," Vol. 1, 2nd Ed., Academi:: Press, New York, N.Y., 1963, p. 153.

6. E.A. Jones, T.F. Parkinson, and T.G. Burke, J. Chem. Phys., 18, $235(1950)$.

7. H.H. Claassen, B. Weinstock, and J.G. Malm, J. Chem. Phys., 28, 285 (1958).

8. D.F. Smith, G.M. Begun, and W.H. Fletcher, Spectrochim. Acta, 20, $1763(1964)$.

9. A.H. Nielsen and P.J.H. Woltz, J. Chem. Phys., 20, 1878 (1952).

10. P.J.H. Woltz and A.H. Nielsen, J. Chem. Phys., 20, 307 (1952).

11. K. Nakamoto, "Infrared and Raman Spectra of Inorganic and Coordination Compounds," 3rd Ed., Wiley (Interscience), New York, N.Y., 1978 , p. 136 .

12. P.H. Citrin, R.W. Shaw, Jr., and T.D. Thomas, in "Electron Spectroscopy," D.A. Shirley, Ed., North-Holland Publishing Co., Amsterdam, and American Elsevier, New York, N.Y., 1972, p. 105.

13. T.D. Thomas and R.W. Shaw, Jr., J. Electron Spectrose. Relat. Phenom., 5, 1081 (1974).

14. G. Johansson, J. Hedman, A. Berndtsson, M. Klasson, and R. Nilsson, J. Electron Spectrosc. Relat. Phenom., 2, 295 (1973).

15. I wish to thank Ms. Gerri Richmond of the UCB Chemistry Department for kindly providing a sample of CIF.

16. K. Siegbahn, et al, "ESCA Applied to Free Molecules," NorthHolland Publishing Co., Ams terdam, and American Elsevier, New York, N.Y., 1969.

17. W.L. Jolly, in "Electron Spectroscopy," D.A. Shirley, Ed., NorthHolland Publishing Co., Amsterdam, and American Elsevier, New York, N.Y., 1972, p. 629. 
18. C.E. Moore, Nat. Stand. Ref. Data Ser., Nat. Bur. Stand., No. 34 (1970).

19. F.A. Cotton and G. Wilkinson, "Advanced Inorganic Chemistry," 3rd Ed., Interscience, New York, N.Y., 1972, p. 117.

20. C.C. Lu, T.A. Carlson, F.B. Nalik, T.C. Tucker, and C.W. Nestor, Jr., Atomic Data, 3 , 1 (1971). 


\section{ACKNOWLEDGMENTS}

I want to express my sincere thanks to Professor William L.

Jolly from whom I have learned much inorganic chemistry. He guided my research efforts with many constructive comments and insightful suggestions.

I would like to thank Professor T. Darrah Thomas and Dr. Herle Millard for their experimental assistance with several aspects of my research.

I am indebted to all the members of the Jolly research group-graduate students and postdoctoral associates, past and present--for the friendship and assistance they provided during the last five years. I am especially grateful to Or. Winfield Perry for his technical assistance during the early stages of my graduate studies.

Finally, I am grateful for the support and encouragement of my wife Christina, my family, and my friends during this period of my life.

This work was supported by the Division of Chemical Sciences, Office of Basic Energy Sciences, U.S. Department of Energy, and by the National Science Foundation. 